\title{
Que significados tem a sexualidade? Um estudo qualitativo
}

\section{Rita Castro ${ }^{1}$}

${ }^{1}$ Instituto Português de Psicologia e Outras Ciências, Porto, Portugal | a.r.f.c@hotmail.com | https://orcid.org/0000-0002-8841-400X

\begin{abstract}
Resumo: A sexualidade é uma área fundamental na vida. Dado este ser um aspeto muito individual de cada pessoa, este estudo procurou conhecer quais os significados que são associados à sexualidade. Nomeadamente, qual o núcleo central e periféricos do termo "sexualidade" e quais as classes de significados que emergem. Para isso foi utilizada uma metodologia qualitativa, com recurso à Técnica de Associação Livre de Palavras. Participaram 1053 pessoas (838 do género feminino, 204 do género masculino e 11 de género não-binário) com uma média de 30.56 anos de idade $(D P=11.01)$. Os dados foram tratados com o software de análise textual IRaMuTeQ. A partir da análise de frequência concluiu-se que as cinco palavras mais ditas foram: prazer $(n=537)$, sexo $(n=496)$, intimidade $(n=449)$, amor $(n=440)$ e relação $(n=115)$. A análise prototípica permitiu compreender uma centralidade na concetualização da sexualidade em torno dos conceitos de prazer, sexo, intimidade e amor, com núcleos periféricos associados a relação, desejo, carinho, autoestima, diversão e casal. A análise da Classificação Hierárquica Descendente indicou um agrupamento dos significados da sexualidade em quatro classes: 1) Envolvimento; 2) Partilha; 3) Afeto; e 4) Expressão, em duas ramificações. A metodologia qualitativa através da TALP permitiu obter as evocações suscitadas acerca da sexualidade, de onde, a partir do conjunto de resultados das várias análises textuais, foi possível encontrar a existência de diferentes significados da sexualidade, que serão mais-valias a ser considerados na intervenção, desde os programas educativos até às intervenções clínicas, para melhor intervir procurando conhecer os significados da sexualidade no contexto.
\end{abstract}

Palavras-chave: Investigação Qualitativa; Análise Textual; Significados; Sexualidade; Portugal.

\section{What does sexuality mean? A qualitative study}

Abstract: Sexuality is a fundamental dimension in life. Given that this is a very individual aspect of each person, this study sought to know which meanings are associated with sexuality. Namely, what is the central and peripheral core of the term "sexuality" and what are the classes of meanings that emerge. For this, a qualitative methodology was used, using the Free Word Association Technique. Participated 1053 people (838 female, 204 male and 11 non-binary) with an average age of 30.56 years $(S D=11.01)$. The data were treated with the textual analysis software IRaMuTeQ. From the frequency analysis it was concluded that the five most spoken words were: pleasure $(n=537)$, sex $(n=496)$, intimacy $(n=449)$, love $(n=440)$ and relationship $(n=115)$. The prototypical analysis allowed us to understand a centrality in the conceptualization of sexuality around the concepts of pleasure, sex, intimacy, and love, with peripheral nuclei associated with relationship, desire, affection, self-esteem, fun and couple. The analysis of the Descending Hierarchical Classification indicated a grouping of the meanings of sexuality in four classes: 1) Involvement; 2) Sharing; 3) Affection; and 4) Expression, in two branches. The qualitative methodology through TALP allowed to obtain the evocations raised about sexuality, where, from the set of results of the various textual analyses, it was possible to find the existence of different meanings of sexuality, which will be added value to be considered in the intervention, from educational programs to clinical interventions, to better intervene seeking to know the meanings of sexuality in the context.

Keywords: Qualitative Research; Textual Analysis; Meanings; Sexuality; Portugal.

\section{Introdução}

A Organização Mundial de Saúde, em 1992, definia sexualidade como fundamental à saúde numa concetualização alargada onde se reflete que é uma "energia que nos motiva a procurar amor, contacto, ternura e intimidade; que se integra no modo como nos sentimos, movemos, tocamos e somos tocados; é ser-se sensual e ao mesmo tempo sexual; influencia pensamentos, sentimentos, ações e interações". 
Em 2002, a definição é atualizada definindo-se sexualidade como "um aspeto central do ser humano ao longo da vida e inclui sexo, identidades e papéis de género, orientação sexual, erotismo, prazer, intimidade e reprodução. A sexualidade é experienciada e expressa em pensamentos, fantasias, desejos, crenças, atitudes, valores, comportamentos, práticas, papéis e relações. Embora a sexualidade possa incluir todas estas dimensões, nem sempre elas são todas experienciadas ou expressas. A sexualidade é influenciada pela interação de fatores biológicos, psicológicos, sociais, económicos, políticos, culturais, éticos, históricos, religiosos e espirituais" (World Health Organization, 2006, p. 5).

Tal denota como se trata de um conceito muito lato, para além do sexo (i.e., atividade/relação sexual) e da reprodução. $E$, como a sexualidade é vivida numa influência de múltiplos fatores, com impacto na saúde global ao longo da vida.

Cada vez mais a sociedade mostra abertura diante da sexualidade e uma conceituação e abordagem positivas. Ainda assim, continuam a ser notórias as dificuldades na expressão livre da sexualidade. Muitas pessoas ainda continuam a ser discriminadas por meio da sua orientação sexual e/ou identidade de género, sobretudo, em virtude de preconceitos, geradores de atitudes e comportamentos de ódio, como a homofobia e transfobia.

Assim, esta investigação, procurou, através da metodologia qualitativa, responder à questão: quais são os significados da sexualidade?

\subsection{Conceito de Sexualidade}

"Estamos perante uma pergunta difícil de responder: o que é a sexualidade" já diziam López e Fuertes $(1989$, p.8). É uma tarefa desafiante pela interligação da sexualidade a diversas áreas de conhecimento e pela dependência tão individual da própria vivência.

Entende-se que existem diversas dimensões que impactam o modo de pensar, sentir, e viver a sexualidade. Que varia ao longo do ciclo de vida, da história, da cultura, do contexto.

Weeks (2003) definiu cinco dimensões na organização social da sexualidade: o sistema família (casamento, parentalidade, relações não heterossexuais, divórcio, sexo nãoreprodutivo); organização socioeconómica (jornada de trabalho, independência financeira); regulação social formal/informal (religião, medicina, duplo padrão sexual, rituais de humilhação pública); contexto político (lei de casamento, interrupção voluntária da gravidez); e cultura de resistência (contraceção, movimentos feministas, direitos homossexuais). A vivência da sexualidade está ancorada no contexto sociohistoricocultural, com influências da economia, política, e regulada pelas interações sociais, com uma expressão pessoal. Sendo os significados que atribuímos à sexualidade uma construção pessoal contextual (Parker, 2009).

A significação da sexualidade está intimamente interligada com a experiência pessoal inserida num determinado contexto sociohistoricocultural, fazendo com que a experiência universal da sexualidade seja uma vivência muito particular. Fará mais sentido falar de sexualidades. O significado da sexualidade é uma realidade pessoal, pelo que a existência será de significados de sexualidades, diversas, individuais a cada pessoa (Pontes, 2011).

O sexo é uma parte da sexualidade. Mas mesmo sem sexo continua a existir sexualidade. A sexualidade acompanha-nos em toda a vida, desde o nascimento à morte, adotando várias expressões e vivências. A sexualidade inclui o sexo (genitais e atividade sexual); a identidade (o sentido identitário de ser masculino, feminino, binário, não-binário, nenhum, qualquer) e o papel de género (o socialmente expectável de acordo com o género); a orientação sexual (o sentido de atração heterossexual, gay, lésbica, pansexual, assexual, bissexual); a autoestima (a ideia que temos do corpo); a experiência sexual; a influência da representação sexual nos media, redes sociais; a experiência de intimidade, confiança, compaixão, amor (Sexuality Resource Center for Parents, 2021). 
Em Portugal, analisou-se a representação social de sexo com uma centralidade das noções de amor e prazer (Gomes \& Nunes, 2015). Pela proximidade com o conceito de sexualidade poderá esperar-se semelhança nuclear. A sexualidade está intimamente relacionada ao processo de socialização, sendo socialmente construída a sua representação e significados. A representação social de sexualidade quando analisada de um ponto de vista geracional revelou convergência de aspetos de modernidade e tradicionalismo (Trindade, 2020).

A sexualidade é um elemento que confere sentido e significado à existência vital humana. $\mathrm{E}$, a identidade de género será um aspeto a considerar na análise dos significados da sexualidade. No género feminino poderá observar-se uma definição da sexualidade mais relacionada aos fatores biopsicossociais, com ênfase no afeto e no prazer (Vieira et al., 2016). Sendo a sexualidade uma vivência desenvolvimental em transformação em todo o ciclo de vida, a idade será um aspeto a analisar no entendimento dos significados. À medida que a idade avança poderão produzir-se significados mais relacionados ao amor, afeto, respeito e companheirismo (Queiroz et al., 2015).

\section{Metodologia}

Este estudo adotou uma metodologia qualitativa, com recurso à Técnica de Associação Livre de Palavras (TALP). O uso do método qualitativo, em específico através da TALP, tem mais-valias no entendimento dos significados atribuídos aos construtos sociais assentes na dinâmica de evocação. A TALP permite o enunciar de forma livre, direta e simples dos significados latentes associados a um significante salientado (Abric, 2003), neste caso "sexualidade".

\subsection{Participantes}

Através de uma amostragem não probabilística, pela técnica de bola de neve, colaboraram 1053 pessoas adultas, da população geral, com uma média de 30.56 anos de idade $[D P=11.01$; mínimo=18 $(n=28)$; máximo=76 $(n=1)]$. A grande maioria das pessoas revelou identificar-se com o género feminino ( $n=838: 79.6 \%)$, seguido de masculino ( $n=204: 19.4 \%)$ e não-binário $(n=11: 1 \%)$. Relativamente a orientação sexual, a maioria das pessoas indicou orientação heterossexual ( $n=898: 85.3 \%)$, seguida de bissexual ( $n=100: 9.5 \%)$, outra $(n=18: 1.7 \%)$, lésbica, $(n=17: 1.6 \%)$, gay $(n=17: 1.6 \%)$ e assexual $(n=3: 0.3 \%)$. Quanto ao estado civil, a maioria indicou solteiro $(n=662: 62.9 \%)$, seguido de casado ( $n=198: 18.8 \%)$, união de facto/coabitação $(n=139: 13.2 \%)$, divorciado $(n=37: 3.5 \%)$ e outro ( $n=16: 1.5 \%)$. Na situação relacional, a grande maioria indicou ter relação íntima com um/a parceiro/a ( $n=717: 68.1 \%)$, seguida de sem relação $(n=294: 27.9 \%)$, relação íntima com mais do que um/a parceiro/a ( $n=28: 2.7 \%)$ e outra ( $n=14: 1.3 \%)$. Relativamente a educação, a grande maioria das pessoas tinha habilitação de nível superior $(n=814: 77.3 \%)$, seguida de secundária $(n=223: 21.2 \%)$, outra $(n=8: 0.8 \%)$ e básica $(n=8: 0.8 \%)$. Em termos de situação profissional, a maioria encontrava-se empregada ( $n=475: 45.1 \%$ ), seguida de estudante ( $n=336: 31.9 \%)$, trabalhadora-estudante $(n=140: 13.3 \%)$, desempregada $(n=89: 8.5 \%)$, reformada $(n=8: 0.8 \%)$ e outra $(n=4: 0.4 \%)$. As pessoas participantes tinham nacionalidade portuguesa $(n=993: 94.3 \%)$ ou estavam a residir em Portugal ( $n=1038: 98.6 \%)$, maioritariamente na zona Norte $(n=703: 66.8 \%)$, seguida de Lisboa e Vale do Tejo $(n=146: 13.9 \%)$, Centro $(n=140: 13.3 \%)$, Açores $(n=18: 1.7 \%)$, Alentejo ( $n=12: 1.1 \%)$, Madeira $(n=10: 0.9 \%)$ e Algarve $(n=9: 0.9 \%)$. 


\subsection{Materiais}

- Significados da Sexualidade: Através da TALP para evocação foi pedida a indicação de cinco palavras/expressões que surgissem espontaneamente na mente ao pensar em "sexualidade". Também foi pedido que fosse indicada a positividade de cada palavra/expressão (numa escala de Likert de cinco pontos $1=$ muito negativa a $5=$ muito positiva).

- Questionário Sociodemográfico: Recolheram-se informações de caracterização geral da amostra. Como idade, género, orientação sexual, estado civil, situação relacional, situação profissional, nível de habilitações, nacionalidade e zona de residência.

\subsection{Procedimentos}

$\mathrm{Na}$ presente investigação, o uso da metodologia qualitativa através da TALP era fundamental para o objetivo da investigação. Esta técnica oferece a mais-valia de permitir conhecer de forma mais espontânea, através da evocação livre, os termos que surgem associados à sexualidade.

- Ética e Deontologia: As pessoas participantes tiveram conhecimento do propósito da investigação, por intermeio do consentimento informado, onde se ressalvava a garantia da confidencialidade e anonimato, bem como, a participação voluntária e possível de terminar a qualquer momento, sem qualquer penalização. Um e-mail foi deixado à disposição para contacto, se necessário.

- Recolha de Dados: A recolha de dados ocorreu por meio de um questionário online de autorrelato através da plataforma SurveyMonkey entre dezembro de 2020 e janeiro de 2021. A divulgação foi feita através de partilhas por e-mail, redes sociais (Linkedln e Instagram), SMS, WhatsApp, bem como, contacto com instituições e organizações de saúde e ensino.

- Análise de Dados: Numa primeira fase, foi necessário realizar a uniformização de palavras (i.e., eliminar artigos/proposições, uniformizar a escrita), um procedimento habitual na TALP (Rosenberg \& Jones, 1972). Posteriormente, a análise textual foi operada no software IRaMuTeQ (Ratinaud, 2009), que revela precisão estatística e possibilita uma grande variedade de análises textuais. Como a análise de frequência, com ilustração pela nuvem de palavras; a análise prototípica, evidenciando o núcleo central e periféricos; e a organização em agrupamentos de palavras através da análise de Classificação Hierárquica Descendente (CHD) (Camargo \& Justo, 2013). A nuvem de palavras permite uma visão geral da frequência de evocação das palavras, com maior destaque para as mais citadas. A CHD é uma análise composta da associação entre os segmentos textuais semelhantes em classes, de onde resulta um dendrograma com a composição de cada classe, com as palavras e a respetiva força de associação com a classe (Camargo \& Justo, 2013). Analisou-se também a associação de cada classe com o conjunto de variáveis sociodemográficas (idade, género, orientação sexual, estado civil, situação relacional). Para a idade foi necessário criar grupos de faixas etárias, tendo-se agrupado nos seguintes: 18-24 jovem, 25-29 adultez jovem, 30-45 adultez madura, 46-65 adultez meia idade, 66+ adultez velhice. Para análise descritiva da amostra e da positividade das palavras citadas foi utilizado o software SPSS. 


\section{Resultados}

\subsection{Análise de Frequência}

No total, foram citadas 5265 palavras (645 formas diferentes e 349 formas evocadas apenas uma vez). A análise de frequência, complementada pela ilustração da nuvem de palavras (Figura 1), permitiu concluir que as dez palavras mais citadas foram: prazer $(n=537)$, sexo $(n=496)$, intimidade $(n=449)$, amor $(n=440)$, relação $(n=115)$, desejo ( $n=103)$, liberdade $(n=89)$, carinho $(n=85)$, sensualidade $(n=81)$ e corpo $(n=80)$.

A análise de frequência de cada palavra, pela sua ordem de evocação, evidenciou que, em primeiro, as cinco palavras mais citadas foram sexo $(n=269)$, intimidade $(n=140)$, amor $(n=129)$, prazer $(n=126)$ e liberdade $(n=21)$. Em segundo, as cinco palavras mais citadas foram prazer $(n=144)$, intimidade $(n=126)$, amor $(n=106)$, sexo $(n=85)$ e desejo $(n=23)$. Em terceiro, as cinco palavras mais citadas foram prazer $(n=116)$, amor $(n=81)$, intimidade ( $n=78)$, sexo $(n=63)$ e relação $(n=25)$. Em quarto, as cinco palavras mais citadas foram prazer $(n=87)$, amor $(n=69)$, intimidade $(n=66)$, sexo $(n=49)$ e relação $(n=28)$. E, em quinto, as cinco palavras mais citadas foram prazer $(n=64)$, amor $(n=55)$, intimidade $(n=39)$, sexo $(n=30)$ e confiança $(n=22)$.

As palavras citadas apresentaram elevada positividade $(M=4.48, \quad D P=0.64)$, independentemente da ordem de evocação.

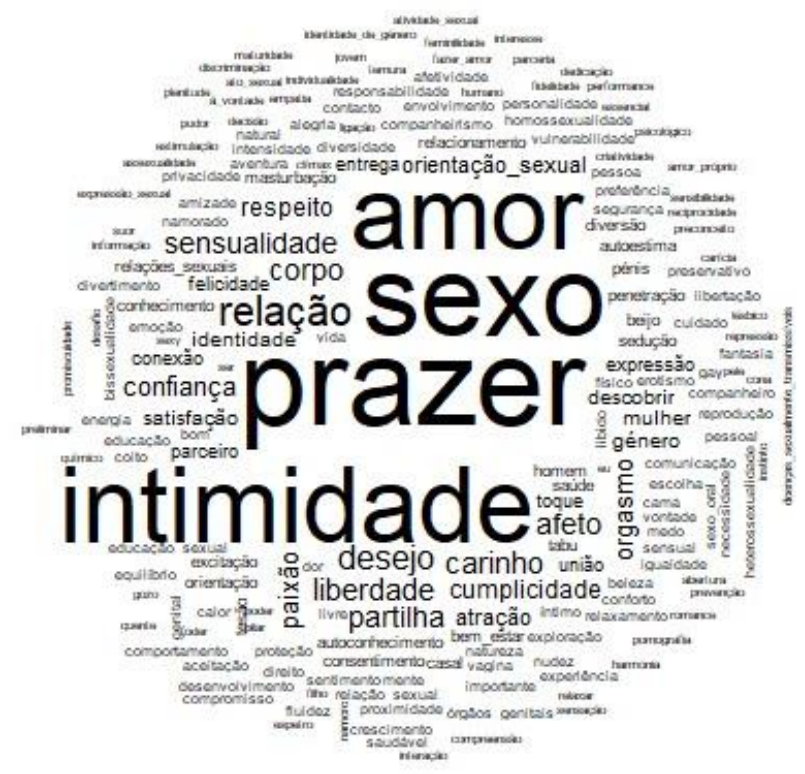

Fig. 1. Nuvem de palavras.

- Análise de Frequência por Género. Quando analisada a frequência considerando o ponto de vista da identificação de género, as cinco palavras mais citadas pelas pessoas de género feminino foram prazer $(n=424)$, sexo $(n=393)$, amor $(n=359)$, intimidade $(n=352)$ e relação $(n=86)$. Pelas pessoas de género masculino foram prazer $(n=107)$, sexo $(n=101)$, intimidade $(n=93)$, amor $(n=75)$ e relação $(n=29)$. E, pelas pessoas de género não-binário foram prazer $(n=6)$, amor $(n=6)$, intimidade $(n=4)$, companheirismo $(n=2)$ e união $(n=2)$.

$\mathrm{Na}$ Tabela 1 pode encontrar-se uma análise de frequência complementar, com as primeiras três palavras mais citadas por género em cada ordem de evocação.

Relativamente à positividade das palavras, não foram encontradas diferenças de género (feminino, $M=4.49$; masculino, $M=4.44, p=0.254$ ). 
Tabela 1. Frequência das palavras segundo o género por ordem de evocação.

\begin{tabular}{|c|c|c|c|}
\hline & Feminino & Masculino & Não-Binário \\
\hline \multirow{4}{*}{ Palavra 1} & sexo $(n=192)$ & $\operatorname{sexo}(n=73)$ & $\operatorname{sexo}(n=4)$ \\
\hline & intimidade $(n=128)$ & amor $(n=26)$ & atração $(n=1)$ \\
\hline & prazer $(n=106)$ & prazer $(n=20)$ & espetro $(n=1)$ \\
\hline & prazer $(n=113)$ & $\operatorname{prazer}(n=31)$ & assexualidade $(n=1)$ \\
\hline \multirow[t]{3}{*}{ Palavra 2} & intimidade $(n=101)$ & intimidade $(n=25)$ & corpo $(n=1)$ \\
\hline & amor $(n=89)$ & amor $(n=17)$ & demissexual $(n=1)$ \\
\hline & prazer $(n=90)$ & prazer $(n=26)$ & intimidade $(n=2)$ \\
\hline \multirow[t]{3}{*}{ Palavra 3} & amor $(n=64)$ & amor $(n=16)$ & amor $(n=1)$ \\
\hline & intimidade $(n=63)$ & intimidade $(n=13)$ & assexualidade $(n=1)$ \\
\hline & prazer $(n=73)$ & amor $(n=14)$ & amor $(n=2)$ \\
\hline \multirow[t]{3}{*}{ Palavra 4} & intimidade $(n=57)$ & prazer $(n=14)$ & diversidade $(n=1)$ \\
\hline & amor $(n=53)$ & $\operatorname{sexo}(n=13)$ & expressão $(n=1)$ \\
\hline & prazer $(n=54)$ & $\operatorname{sexo}(n=14)$ & prazer $(n=2)$ \\
\hline \multirow[t]{2}{*}{ Palavra 5} & amor $(n=49)$ & intimidade $(n=11)$ & confiança $(n=1)$ \\
\hline & intimidade $(n=28)$ & prazer $(n=8)$ & corpo $(n=1)$ \\
\hline
\end{tabular}

\subsection{Análise de Classificação Hierárquica Descendente}

Do corpus geral constituído por 5265 ocorrências, separadas por 1053 segmentos de texto (ST), foram aproveitados para análise 928 ST, representando $88.13 \%$ do total. O conteúdo textual revelou-se agrupado em quatro classes: Classe 1 Envolvimento; Classe 2 Partilha; Classe 3 Afeto; e Classe 4 Expressão, que se encontram dividas por duas ramificações e uma sub-ramificação (Figura 2).

- Classe 1 - Envolvimento. É a maior classe, com 271 ST (29.2\%), integrando palavras como desejo $\left(X^{2}=70.86\right)$, orgasmo $\left(X^{2}=55.87\right)$, excitação $\left(X^{2}=52.09\right)$, sexo $\left(X^{2}=50.19\right)$, sensualidade $\left(X^{2}=38.86\right)$ e satisfação $\left(X^{2}=33.57\right)$. Predominando palavras indicadas por pessoas em situação civil de casamento $\left(X^{2}=5.95\right)$ ou união de facto $\left(X^{2}=3.99\right)$.

- Classe 2 - Partilha. Contém 245 ST $(26.4 \%)$ incluindo palavras como intimidade $\left(X^{2}=69.55\right)$, confiança $\left(x^{2}=57.31\right)$, parceiro $\left(X^{2}=37.79\right)$, prazer $\left(X^{2}=37.41\right)$, descobrir $\left(X^{2}=32.05\right)$ e consentimento $\left(x^{2}=22.34\right)$. Predominando palavras indicadas por pessoas na faixa etária desenvolvimental da idade da adultez madura $\left(X^{2}=4.39\right)$.

- Classe 3 - Afeto. É a menor classe, com 159 ST (17.13\%), contendo palavras como carinho $\left(X^{2}=119.2\right)$, cumplicidade $\left(X^{2}=112.5\right)$, respeito $\left(X^{2}=102.1\right)$, união $\left(X^{2}=72.03\right)$, companheirismo $\left(X^{2}=68.75\right)$ e amor $\left(X^{2}=57.94\right)$. Predominando palavras indicadas por pessoas que se identificam com género não binário $\left(X^{2}=9.45\right)$ e orientação sexual lésbica $\left(X^{2}=4.76\right)$.

- Classe 4 - Experiência. Agrupa 253 ST (27.26\%) integrando palavras como género $\left(X^{2}=102.8\right)$, identidade $\left(X^{2}=99.92\right)$, orientação sexual $\left(X^{2}=99.61\right)$, expressão $\left(X^{2}=51.36\right)$ e orientação $\left(X^{2}=42.6\right)$. Predominando palavras indicadas por pessoas em situação civil de solteiro $\left(X^{2}=35.95\right)$. 


\begin{tabular}{|c|c|c|c|c|c|c|c|}
\hline \multicolumn{2}{|c|}{ Classe 1} & \multicolumn{2}{|c|}{ Classe 2} & \multicolumn{2}{|l|}{ Classe 3} & \multicolumn{2}{|l|}{ Classe 4} \\
\hline \multicolumn{2}{|c|}{ Envolvimento } & \multicolumn{2}{|c|}{ Partilha } & \multicolumn{2}{|l|}{ Afeto } & \multicolumn{2}{|c|}{ Expressão } \\
\hline \multirow{2}{*}{\multicolumn{2}{|c|}{$\begin{array}{c}(29.20 \%) \\
271 \mathrm{ST}\end{array}$}} & \multicolumn{2}{|c|}{$(26.40 \%)$} & \multicolumn{2}{|l|}{$(17.13 \%)$} & \multicolumn{2}{|l|}{$(27.26 \%)$} \\
\hline & & \multicolumn{2}{|c|}{$245 \mathrm{ST}$} & \multicolumn{2}{|l|}{$159 \mathrm{ST}$} & \multicolumn{2}{|l|}{$253 \mathrm{ST}$} \\
\hline Palavras & $x^{2}$ & Palavras & $x^{2}$ & Palavras & $x^{2}$ & Palavras & $x^{2}$ \\
\hline desejo & 70.86 & intimidade & 69.55 & carinho & 119.15 & género & 102.81 \\
\hline orgasmo & 55.87 & confiança & 57.31 & cumplicidade & 112.51 & identidade & 99.92 \\
\hline excitação & 52.09 & parceiro & 37.79 & respeito & 102.13 & orientação sexual & 99.61 \\
\hline sexo & 50.19 & prazer & 37.41 & união & 72.03 & expressão & 51.36 \\
\hline sensualidade & 38.86 & descobrir & 32.05 & companheirismo & 68.75 & orientação & 46.20 \\
\hline satisfação & 33.57 & consentimento & 22.34 & amor & 57.94 & relações sexuais & 25.18 \\
\hline paixão & 33.09 & bem-estar & 20.24 & alegria & 48.89 & casal & 35.18 \\
\hline masturbação & 27.83 & saúde & 20.00 & amizade & 39.03 & escolha & 35.18 \\
\hline cama & 24.51 & relaxamento & 19.66 & af eto & 34.17 & diversidade & 35.18 \\
\hline namorado & 24.51 & conforto & 19.66 & companheiro & 24.31 & íntimo & 32.44 \\
\hline felicidade & 22.80 & entrega & 19.09 & cuidado & 23.36 & mente & 21.53 \\
\hline bom & 22.03 & partilha & 18.73 & aventura & 23.36 & energia & 21.53 \\
\hline tesão & 21.96 & autoestima & 17.28 & sensibilidade & 19.43 & privacidade & 18.82 \\
\hline atração & 17.24 & vulnerabilidade & 15.50 & partilha & 14.48 & órgãos genitais & 18.82 \\
\hline intensidade & 10.37 & proximidade & 15.50 & & & vontade & 17.40 \\
\hline erotismo & 10.22 & emoção & 14.83 & & & relação & 17.25 \\
\hline & & corpo & 14.53 & & & pessoal & 16.11 \\
\hline & & conexão & 14.04 & & & personalidade & 16.11 \\
\hline & & conhecimento & 12.39 & & & necessidade & 16.11 \\
\hline & & exploração & 12.30 & & & aceitação & 16.11 \\
\hline & & estimulação & 11.20 & & & sentimento & 13.97 \\
\hline & & & & & & preferência & 13.41 \\
\hline & & & & & & direito & 13.41 \\
\hline & & & & & & crescimento & 13.41 \\
\hline & & & & & & saudável & 13.41 \\
\hline & & & & & & reprodução & 13.41 \\
\hline & & & & & & igualdade & 13.41 \\
\hline & & & & & & fisico & 13.41 \\
\hline & & & & & & fluidez & 13.41 \\
\hline & & & & & & livre & 12.15 \\
\hline & & & & & & desenvolvimento & 10.72 \\
\hline & & & & & & preconceito & 10.72 \\
\hline & & & & & & individualidade & 10.72 \\
\hline & & & & & & relacionamento & 10.19 \\
\hline *civil casado & 5.95 & *adult. madura & 4.39 & *género nbinário & & ${ }^{*}$ civil solteiro & 35.95 \\
\hline *civil união & 3.99 & & & *orient. lésbica & & & \\
\hline
\end{tabular}

Fig. 2. Classificação Hierárquica Descendente.

\subsection{Análise de Similitude e Prototípica}

A análise de similitude (Figura 3) auxiliou na compreensão visual da estrutura do corpus textual. É possível confirmar a ênfase das palavras mais evocadas: prazer, sexo, intimidade e amor. Com a centralidade de prazer de onde emergem os outros núcleos de significado e palavras significativas associadas. De prazer surgem palavras como partilha, orgasmo e liberdade; de amor surgem cumplicidade e carinho; de sexo surgem relação, afeto e sensualidade; e de intimidade surgem confiança e conexão. 
Vol. 8 | Investigação Qualitativa em Saúde: Avanços e Desafios

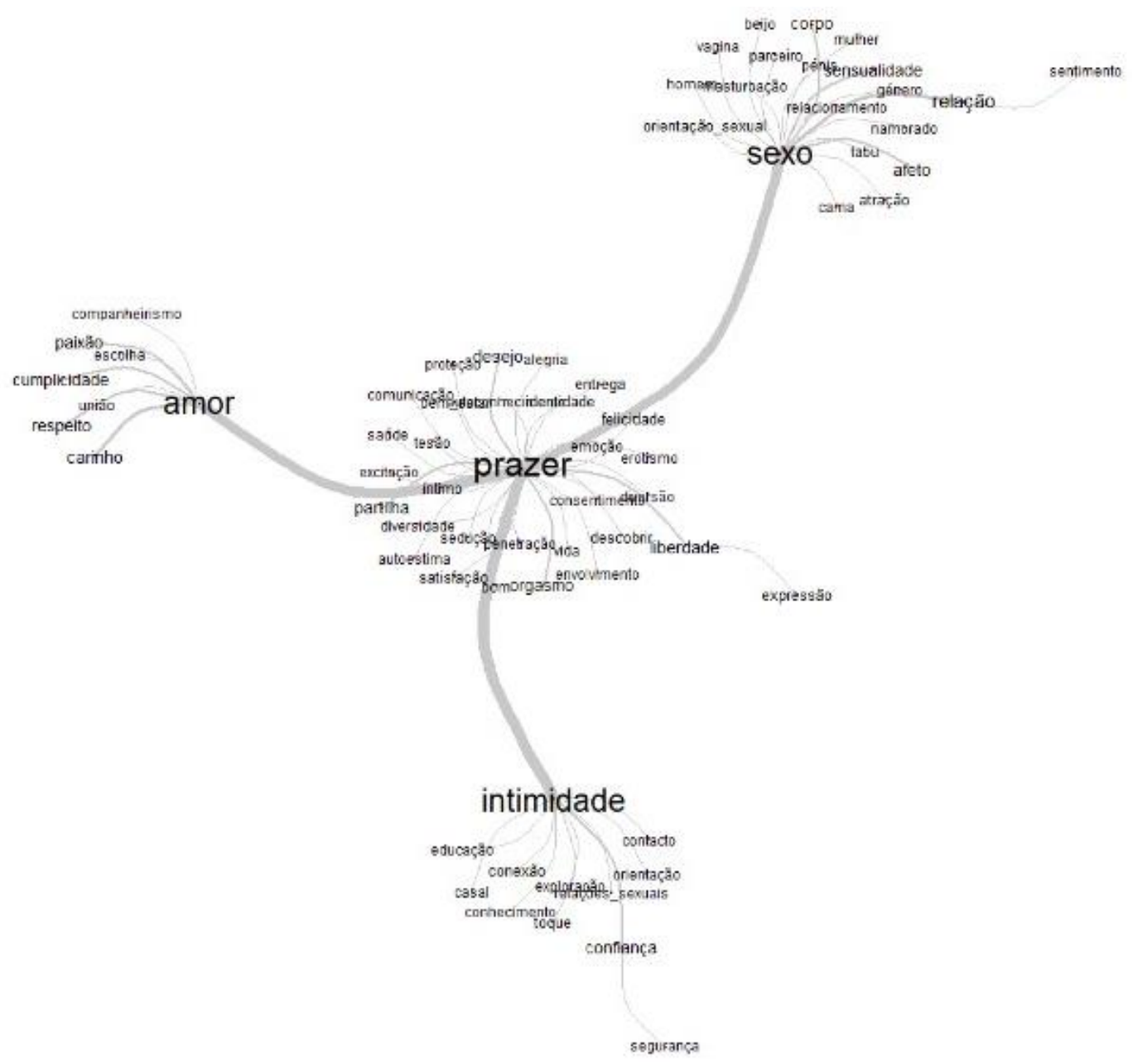

Fig. 3. Análise de similitude-

A análise prototípica reforçou o entendimento da estrutura de concetualização da sexualidade a partir dos critérios de frequência e ordem de evocação. O diagrama (Tabela 2) apresentou as quatro dimensões da representação do construto sexualidade. O primeiro quadrante (elevada frequência e baixa ordem de evocação) traduz o possível núcleo central da sexualidade com as palavras prazer, sexo, intimidade, amor e liberdade. $\mathrm{O}$ segundo quadrante (elevada frequência e maior ordem de evocação) traduz o primeiro núcleo periférico com as palavras relação, desejo, carinho, corpo e partilha. O quarto quadrante (baixa frequência e baixa ordem de evocação) indica a zona de contraste com as palavras relações sexuais, escolha, bom, educação e contacto. $E$, o quarto quadrante (baixa frequência e maior ordem de evocação) indica o segundo núcleo periférico com as palavras autoestima, diversão, casal, íntimo e erotismo. 
Vol. 8 | Investigação Qualitativa em Saúde: Avanços e Desafios

Tabela 2. Análise prototípica das palavras evocadas para "sexualidade".

\begin{tabular}{|c|c|c|c|c|c|}
\hline \multicolumn{3}{|c|}{ Núcleo Central } & \multicolumn{3}{|c|}{ Primeiro Núcleo Periférico } \\
\hline Palavra & $f \geq 17$ & OME $\leq 2.9$ & Palavra & $f \geq 21$ & OME $\leq 4.1$ \\
\hline Prazer & 537 & 2.7 & Relação & 115 & 3.1 \\
\hline Sexo & 496 & 2.0 & Desejo & 103 & 3.1 \\
\hline Intimidade & 449 & 2.4 & Carinho & 85 & 3.3 \\
\hline Liberdade & 89 & 2.9 & Corpo & 80 & 3.0 \\
\hline Sensualidade & 81 & 2.9 & Partilha & 76 & 3.4 \\
\hline Afeto & 77 & 2.7 & Confiança & 70 & 3.5 \\
\hline Orientação sexual & 48 & 2.6 & Orgasmo & 67 & 3.6 \\
\hline Género & 41 & 2.6 & Paixão & 65 & 3.4 \\
\hline Mulher & 35 & 2.6 & Cumplicidade & 60 & 3.5 \\
\hline Expressão & 34 & 2.6 & Respeito & 55 & 3.5 \\
\hline Homem & 21 & 2.8 & Atração & 53 & 3.0 \\
\hline Sedução & 17 & 2.7 & Descoberta & 42 & 3.4 \\
\hline Tesão & 17 & 2.8 & Satisfação & 39 & 3.3 \\
\hline \multirow[t]{15}{*}{ Pénis } & 17 & 2.8 & Identidade & 37 & 3.5 \\
\hline & & & Entrega & 34 & 3.6 \\
\hline & & & Parceiro & 32 & 3.2 \\
\hline & & & Toque & 29 & 3.3 \\
\hline & & & Felicidade & 28 & 3.9 \\
\hline & & & Relações & 28 & 3.1 \\
\hline & & & Conexão & 28 & 3.1 \\
\hline & & & União & 27 & 4.1 \\
\hline & & & Masturbação & 24 & 3.6 \\
\hline & & & Autoconhecimento & 24 & 3.2 \\
\hline & & & Excitação & 23 & 3.4 \\
\hline & & & Saúde & 23 & 3.2 \\
\hline & & & Bem-estar & 22 & 3.5 \\
\hline & & & Conhecimento & 22 & 3.5 \\
\hline & & & Beijo & 21 & 3.1 \\
\hline \multicolumn{3}{|c|}{ Zona de Contraste } & \multicolumn{3}{|c|}{ Segundo Núcleo Periférico } \\
\hline Palavra & $f \geq 2$ & OME $\leq 2.9$ & Palavra & $f \geq 8$ & OME $\leq 4.7$ \\
\hline Relações sexuais & 16 & 2.6 & Autoestima & 16 & 3.6 \\
\hline Escolha & 13 & 2.7 & Diversão & 16 & 3.6 \\
\hline Bom & 11 & 2.5 & Casal & 15 & 3.2 \\
\hline Educação & 10 & 2.9 & Íntimo & 14 & 3.4 \\
\hline Contacto & 9 & 2.6 & Erotismo & 14 & 3.6 \\
\hline Relação sexual & 9 & 2.6 & Emoção & 14 & 3.6 \\
\hline Bissexualidade & 8 & 2.5 & Companheirismo & 14 & 3.3 \\
\hline Sensual & 7 & 2.9 & Vida & 14 & 3.6 \\
\hline Preferência & 6 & 2.5 & Sentimentos & 13 & 3.5 \\
\hline Direito & 6 & 2.3 & Vagina & 13 & 3.6 \\
\hline Heterossexualidade & 6 & 2.3 & Diversidade & 13 & 3.9 \\
\hline Coito & 6 & 2.8 & Proteção & 12 & 4.7 \\
\hline Gay & 5 & 2.0 & Comunicação & 12 & 3.0 \\
\hline Sensações & 4 & 2.8 & Cama & 12 & 3.3 \\
\hline Espetro & 4 & 2.0 & Envolvimento & 11 & 3.7 \\
\hline Preconceito & 4 & 2.8 & Namorado & 11 & 3.9 \\
\hline Repressão & 3 & 2.7 & Exploração & 11 & 3.7 \\
\hline Expressão sexual & 3 & 2.3 & Segurança & 10 & 4.0 \\
\hline Ato sexual & 3 & 2.3 & Alegria & 10 & 3.8 \\
\hline Fazer amor & 3 & 2.7 & Intensidade & 9 & 3.8 \\
\hline Foder & 3 & 2.7 & Educação sexual & 9 & 3.2 \\
\hline Identidade de género & 3 & 1.7 & Vontade & 9 & 3.1 \\
\hline Lésbica & 3 & 2.0 & Mente & 9 & 3.3 \\
\hline Cona & 3 & 1.7 & Energia & 8 & 4.1 \\
\hline Pila & 3 & 1.3 & Proximidade & 8 & 3.5 \\
\hline Gostoso & 2 & 2.5 & Privacidade & 8 & 4.4 \\
\hline Riso & 2 & 2.5 & Importante & 8 & 3.8 \\
\hline Novidade & 2 & 2.5 & Vulnerabilidade & 8 & 3.4 \\
\hline
\end{tabular}




\begin{tabular}{lcc|lcc}
\hline & Núcleo Central & & \multicolumn{3}{c}{ Primeiro Núcleo Periférico } \\
Palavra & $\boldsymbol{f} \geq \mathbf{1 7}$ & OME $\leq \mathbf{2 . 9}$ & Palavra & $\boldsymbol{f} \geq \mathbf{2 1}$ & OME $\leq \mathbf{4 . 1}$ \\
\hline Mamas & 2 & 2.5 & Nudez & 8 & 3.4 \\
Envolvência & 2 & 2.0 & Beleza & 8 & 3.2 \\
Relações íntimas & 2 & 2.0 & Amizade & 8 & 3.6 \\
\hline
\end{tabular}

Nota. OME = Ordem Média de Evocação; $f=$ Frequência

\section{Discussão}

A adoção da metodologia qualitativa, com a TALP, possibilitou a compreensão abrangente dos significados associados à sexualidade. É possível entender, pela análise conjunta dos resultados, a emergência na significância da sexualidade de várias áreas de vivência e influência, o que vai ao encontro da definição atual de sexualidade da WHO (2006).

Destacam-se, com confirmação das várias análises textuais, a centralidade de construtos nucleares na forma de significar a sexualidade, muito relacionados a prazer (associado a libertação), sexo (mais relacionado com a componente física/relacional), intimidade (associada à necessidade de confiança), e amor (mais associado à dimensão sentimental), com semelhança à representação social de sexo (Gomes \& Nunes, 2015). Com suporte nos núcleos periféricos, mais relacionados à exploração e partilha da sexualidade, e zona de contraste, relativa à diversidade de expressão e vivência da sexualidade.

A análise do agrupamento das palavras reforça a noção de uma multiplicidade de contextos de significação e vivência da sexualidade, ao longo de toda a vida, quer do ponto de vista de vivência mais privada, como as Classes Envolvimento, Partilha e Afeto, quer do ponto de vista de vivência mais social, como a Classe Expressão. A classe Expressão aparece com palavras que refletem o domínio da expressão social da sexualidade no seu amplo espetro de possibilidades de vivência, nomeadamente na diversidade de género, identidade de género, orientação sexual, reforçadas pelas noções de direito, necessidade, aceitação e igualdade. No âmbito daquilo que se entende por uma vivência privada, a classe Envolvimento reflete as dinâmicas da vivência sexual a nível psicológico, como o desejo, e fisiológico, como a excitação, também relacionadas a intensidade, sensualidade e erotismo; a classe Partilha remete para a necessidade de uma vivência íntima, com confiança, muitas vezes associada à dinâmica com um parceiro, entrega, com prazer e bem-estar; e a Classe Afeto ilustra a dimensão emocional e relacional da vivência da sexualidade, numa relação de cumplicidade, companheirismo, marcada pelo carinho e respeito, com união e amor.

Ao olhar para as classes que emergiram, percebem-se as várias dimensões que compõem a sexualidade, desde uma dimensão mais privada, com influências da componente da biologia, da psicologia, até uma dimensão mais social, com influência sociocultural e histórica. O que é bastante notório pela classe Expressão, com a sexualidade como veículo de identidade pessoal, com direitos e necessidade de respeito e aceitação, indo ao encontro da concetualização recente (Pontes, 2011; Sexuality Resource Center for Parents, 2021).

Da análise de associação com dimensões sociodemográficas, o género revelou-se como não tendo associação significativa com os significados da sexualidade (em contraste com outras culturas, Vieira et al., 2016). Revela-se semelhança de evocação transversal centrada no prazer, intimidade e sexo, reflexo de transformações sociais modernas (Trindade, 2020). Encontrou-se, apenas, associação com a Classe Afeto, de pessoas que se identificam com género não binário ou orientação sexual lésbica, talvez pela necessidade, devido à vivência discriminatória, de respeito, companheirismo e união. Verificou-se associação da Classe Envolvimento com pessoas casadas ou em união de facto/coabitação, talvez pela fase relacional/de vida, que foca nas dinâmicas da resposta sexual, desde desejo, excitação e orgasmo associadas à noção de satisfação. Percebeuse associação da Classe Partilha a pessoas na faixa etária da adultez madura, o que poderá refletir o maior foco na dinâmica de prazer, de intimidade e confiança (indo ao encontro de outros estudos, Queiroz et al., 2015). 
E, a Classe Expressão surgiu com elevada associação a pessoas solteiras, possivelmente pela nova forma de entender a sexualidade, numa perspetiva mais diversa e plural, afastada da tradição (Trindade, 2020).

Apesar das limitações de amostra, bastante jovem, sobretudo de género feminino, com escolarização elevada e da zona Norte de Portugal, e de recolha no momento mundial pandémico, que requerem cautela na generalização, e necessidade de melhor aprofundar a análise segundo o género, este estudo traz informação que deve ser considerada, quando abordamos a temática da sexualidade, quer do ponto de vista da educação sexual, quer do ponto de vista da intervenção terapêutica sexual. Torna-se mais clara a necessidade de procurar conhecer o entendimento da pessoa acerca da sexualidade para melhor intervir de forma ajustada ao contexto real. E, nas abordagens da educação sexual, como notado pelas várias áreas de significados da sexualidade, não podemos continuar a focalizar as intervenções apenas nas questões do Envolvimento, como a resposta sexual, a reprodução. Temos, também, de educar e intervir nas questões da dinâmica relacional, como consentimento, e da expressão social, como identidades e orientações sexuais, bem como, direitos e necessidades.

Pela evocação no discurso de diversos significados, que vêm corroborar os desafios de definição da sexualidade, como construto amplo e de significado idiossincrático (Parker, 2009; Pontes, 2011), é necessário continuar a investigação, porque a linguagem é veículo de entendimento e codificação da realidade envolvente. E, portanto, é preciso compreender, por exemplo, como os modos de pensar a sexualidade impactam a sua vivência, procurando conhecer a associação com variáveis da saúde sexual (como prazer sexual, desejo sexual, satisfação sexual).

\section{Conclusão}

Através da abordagem qualitativa com a TALP, que permitiu a evocação livre dos significados associados à sexualidade, e pelo desenvolvimento de análises textuais diversas de resultados complementares, foi possível melhor aprofundar e compreender os significados da sexualidade, tornando mais segura e completa a derivação de conhecimento. Concluindo-se pela centralidade na significação da sexualidade das noções de prazer, sexo, intimidade, amor, relação e desejo, em quatro classes principais: Envolvimento, Partilha, Afeto e Expressão. Resultados que poderão ser úteis na melhoria das propostas de intervenção-ação em contexto.

\section{Referências}

Abric, J. C. (2003). L'analyse structurale des représentations sociales. In S. Moscovici \& F. Buschini (Eds.), Les méthodes des sciences humaines (pp. 375-392). Paris: Presses Universitaires de France.

Camargo, B. V., \& Justo, A. M. (2013). IRAMUTEQ: Um software gratuito para análise de dados textuais. Temas em Psicologia, 21(2), 513-518. https://doi.org/10.9788/TP2013.2-16

Gomes, A., \& Nunes, C. (2015). Representação social do sexo nos jovens adultos Portugueses. Psicologia Reflexão e Crítica, 28(1), 177-185. http://dx.doi.org/10.1590/1678-7153.201528119

López, F., \& Fuertes, A. (1999). Para compreender a sexualidade. Lisboa: Associação para o Planeamento Familiar.

Parker, R. (2009). Sexuality, culture and society: Shifting paradigms in sexuality research. Culture, Health \& Sexuality, 11(3), 251-266. https://www.tandfonline.com/doi/abs/10.1080/13691050701606941

Pontes, A. (2011). Sexualidade: Vamos conversar sobre isso? - Promoção do desenvolvimento psicossexual na adolescência: Implementação e avaliação de um programa de intervenção em meio escolar [Tese de Doutoramento Instituto de Ciências Biomédicas Abel Salazar da Universidade do Porto]. https://hdl.handle.net/10216/24432 
Queiroz, M., Lourenço, R., Coelho, M., Miranda, K., Barbosa, R., \& Bezerra, S. (2015). Social representations of sexuality for the elderly. Revista Brasileira de Enfermagem, 68(4), 662-667. https://doi.org/10.1590/0034-7167.2015680413i

Rosenberg, S., \& Jones, R. (1972). A method for investigating and representing a person's implicit theory of personality: Theodore Dreiser's view of people. Journal of Personality and Social Psychology, 22(3), 373-386. https://doi.org/10.1037/h0032891

Sexuality Resource Center for Parents. (2021). A definition of sexuality. Retirado 23 de fevereiro 2021 de http://www.srcp.org/for_all_parents/definition.html

Trindade, I. (2020). Representações sociais de género e sexualidade em Portalegre e Lisboa [Dissertação de Mestrado Instituto Universitário de Lisboa]. https://www.iscte-iul.pt/tese/10443

Vieira, K., Nóbrega, R., Arruda, M., \& Veiga, P. (2016). Representação social das relações sexuais: Um estudo transgeracional entre mulheres. Psicologia: Ciência e Profissão, 36(2), 329-340. https://doi.org/10.1590/1982-3703001752013

Weeks, J. (2003). Sexuality. Nova lorque: Routledge.

World Health Organization. (2006). Defining sexual health: Report of a technical consultation on sexual health, 28-31 January 2002. Geneva: World Health Organization. 